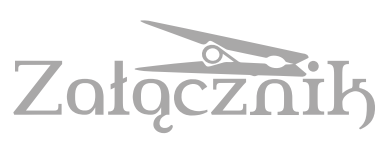

\title{
WHAT IS CULTUROLOGY?
}

EDWARD KASPERSKI

Faculty of Polish Studies,

University of Warsaw

\section{THE CONTEXT, SUBJECT AND CHARACTERISTICS OF CULTUROLOGY}

Culturology deals with a study of culture with the intention to encompass it in its entirety, cognize its complexity and the processes occurring within it as well as identifies the qualities decisive for its hypothetical unity and for its relative difference from the other domains of being. The difficulty in solving the latter issue stems from the fact that - quite literally - the 'entirety' of culture is of tentative, ephemeral, mobile, multi-shaped nature, thus it relentlessly changes its content and boundaries. It is so because its resources include such diverse classes of artifacts - seemingly of no common denominator - as: tools, utensils, machines, means of transportation, architecture, scientific discoveries, works of art, music, texts, customs, institutions, lay and religious rituals, etc. Additionally, all of the above evolve in time and differ according to the type of their society of origin and its spatial context. As a result, it proves much easier to recognize cultures created and practiced by various communities, situated in a specific time and a defined space, than to characterize 'global culture' or 'culture in general'.

1 The origin of the term 'culturology' is in itself complex. The author regarded as its creator is a German scholar Wilhelm Friedrich Ostwald, a chemist and philosopher, Nobel prize laureate in chemistry, and the author of the seminal Energetische Grundlagen der Kulturwissenschaft (1909), who was the first to use the term with regard to culture in 1913. However, renown and wide significance were rendered to the term by an American anthropologist and theorist of culture Leslie A. White (1900-1975). See: Carneiro 2004: 165. The term 'culture' is discussed also by: Ort 2003: 19-20. 
Moreover, the same applies to all the various fields of culture (customs, arts, technology, consumption, etc.), which in contrast to extremely heterogeneous and internally diversified entirety of culture are characterized by a relative uniformity, duration in time and potential for diffusion. Another quality of culture - and concurrently another obstacle in developing a definition thereof - is the fact that it enters into mutable, dynamic relationship with what is considered the extra-cultural domain (at times including nature, religion or science) $)^{2}$. Other difficulties arise from the methods of identification and conceptualisation of the aforementioned entirety. The field is contended for by various aprioristic approaches, descriptive and inductive empirical procedures and comparative studies ${ }^{3}$.

All these inconveniences point to the fact that general characteristics of culture are elusive for definitional immobilization and exhaustion and also that themselves, much like their subject - culture - they undergo cultural relativization. Attempts at finding and reconstructing a uniform, lasting symbolic and/or systematic order of culture, willingly undertaken once by structuralists, are barred by seemingly insurmountable obstacles. They were aptly defined in terms of 'collisions of cultural systems' by the EstonianRussian culture and literary theorist, Yuri Lotman:

The history of the culture of any population may be examined from two points of view: firstly, as an immanent development; secondly, as the result of a variety of external influences. Both these processes are closely intertwined and their separation is only possible in the modality of scientific abstraction. Furthermore, and taking into account the aforesaid, it follows that any isolated examination of either immanent movement of such influences inevitably creates a distorted picture. The complexity does not, however, lie in this factor but rather in the fact that any intersection of systems

2 However, it is true that the extra-cultural domain does specifically influence culture and the symbolic, textual and dialogical expressions can be found in culture (as climate, for instance, motivating couples every day, medial, artistic and scientific discourses of the weather); culture, too, comprehensively influences the form of nature by domesticating animals, agriculture, horticulture, parks, utilization of natural resources or ecological activity.

3 As an example of the latter, one may point to the so-called cross-cultural studies. See: Minkov, Hofstede 2013. 
sharply increases the unpredictability of future movements. The case where an external intrusion leads to victory over one of the colliding systems and suppression of another is far from characteristic of all such events. Sufficiently frequently the collision produces a third, fundamentally new, phenomenon which is not an obvious, logically predictable, consequence of either of the colliding systems. The matter is made more complex by the fact that the newly formed phenomenon appropriates the name of one or other of the colliding structures, such that something which is, in principle, new lies hidden under an old facade (Lotman 2009: 65).

The obstacles in the identification of lasting order of culture are therefore created firstly by its dynamic productivity: the advent of new phenomena, forms and creations in various fields, as well as the falling from circulation of existing or domesticated ones. Another source of interference can in turn be identified as the overlay, mutual blending and motion of diverse patterns, behaviors and artifacts. The driving force behind them tends to include global and regional trans- cultural processes. In the past, the latter were initiated, for instance, by the Christianization of Europe and America, the Islamization of vast lands in Africa and Asia or the Africanization of the American continent due to the import of slaves. To date, they have not ceased to occur, stimulated by the globalization of the market, the Internet or, say, Americanization. In turn, the mutual influence and interpenetration of differing cultures and civilizations - previously mutually incomprehensible, alien or inaccessible - fosters the creation of novel, hybrid cultural formations, as well as the emergence of intercultural ${ }^{4}$ focal points, which constitute an alternative both to the practices of cultural ethnocentrism and of segregation (e.g. in relation to the Aborigines or exotic immigrants) and to the phenomena of acculturation and assimilation by the dominant culture.

However, these transformations do not occur without clashes and conflicts. Idyllic images of a collision-free exchange or harmonious cultural order are disrupted by the practices of imposing hegemony, leveling the distinct features innate for the ethnic, linguistic or religious minorities, subjugated and dependent in terms of military, political and economical

4 The concept of the intercultural was introduced and popularized by: Terkessidis 2010 . 
power. An expression of such attitude came to be known as the praxis of the so- called cultural genocide, applied even today in some regions of Europe, the Middle East, Asia and Africa, as a result of the conviction that traces of a distinct identity and culture within a minority ought to be erased and that culture should conform to the hegemonic social powers.

The above circumstances and processes are the reason why numerous attempts at identifying the 'essence of culture' - as a model for such activity one could regard a forgone book by Alfred Kroeber The Nature of Culture (1952) - often lead to a disappointment ${ }^{5}$. For they draw the charges of normativity and essentialism, as they solidify in such 'essence' the preferred type of culture at the expense of limiting pluralism, diversity or mutability of the respective cultural fields ('subsystems'). Moreover, there are many more traps of the kind for culturology to avoid. Still, that does not justify, as could be supposed, resigning from the search for what constitutes culture as opposed to non-culture, or for what could be considered common in our seemingly motley multiplicity, diversity and mutability of cultures. Negating the idea - albeit only hypothetical - of unity and community of cultures seems rather out of place here, especially when one assumes that such sort of research should not blur the differences between them nor their distinctness. For, although the knowledge of culture could not be exhausted by way of induction, it cannot be encapsulated in a uniform system nor established a priori. What remains is the method of approximations, which admittedly does not aspire to the status of irrefutable knowledge, yet it envisions a certain 'possible' image of culture, able to undergo corrections and falsification. That is therefore the way trodden by culturology (or the way it should progress along).

Hence, it does not renounce rational research procedures, at times charged with logocentrism by the followers of Jaques Derrida. Neither can it be boiled down to detailed empirical studies and those focusing on specific phenomena, e.g. Tadeusz Kantor's theatre, novels by Elfriede Jelinek or graffiti on the city walls of Warsaw. It extends beyond the research

${ }^{5}$ A wide range of definitions of culture put forth from various theoretical standpoints were formerly compiled in the: Kroeber, Kluckhohn 1952. Meanwhile an insightful overview of the proposed definitions from the perspective of culturology was put together in: White 1959. 
of independent areas of culture, e.g. customs, theatre, music, paining, literature, politics or media ${ }^{6}$. It does not limit culture to ethnic enclaves, to mention only the artifacts and customs of Guaycuru and Bororo peoples of South America described by Claude Lévi-Strauss, and other, countless studies by ethnographers, ethnologists and anthropologists. Likewise, it does not confine it to social criteria, to mention in turn the research on the morals of bourgeoisie or sociological studies of neighborly bonds in rural areas. Neither could one identify culturology with the history of culture, despite the attempts of the last couple of decades by Stephen Greenblatt, New Historicism and culture poetics, nor numerous descriptions and efforts made to isolate the separate cultures of antiquity, the Middle Ages, the Renaissance, the Baroque, and the Enlightenment. Culturology does not blend with such sciences within humanities as psychology, sociology, semiotics or anthropology, either. These sciences do indeed focus on cultural phenomena, but they treat it as a general rule derivatively, concentrating instead on their field-specific issues of psyche, group behavior, interpersonal relationships, society, types of signs and sign systems, or generic traits and markers of the human (homo sapiens). Obviously, neither does culturology deal directly with natural and mathematical sciences, which ex definitione direct their attention at non-cultural phenomena.

Thus, the conclusion to be drawn from the above enumeration is that culturology is not concerned with a delineated section of culture, nor any of its pre-defined fields, nor still that or other aspect or function thereof, but on its entirety. The above considerations should not however lead to the inference that culture as such exists and functions outside the realm of the human psyche and activity, out of the bonds humans enter into and their

6 That does not mean that culturology ignores such research. In that respect it honors the principle of deconstruction of the whole as a methodological device, cf. Adam Kuper (1999: 245): 'to understand culture, we must first deconstruct it. Religious beliefs, rituals, knowledge, moral values, the arts, rhetorical genres, and so on should be separated out from each other rather than bound together into a single bundle labeled culture (...)'. It is worth noting that the existence of relatively distinct segments of culture does not abolish the question of the effects they may have upon one another nor their interfusion, nor still their position in the dynamic, ever-changing cultural whole. 
interactions, the society, its institutions, public and private communication, the circulation of signs, languages, texts and discourses. It is not assumed in them either that culture is indifferent to biological and ecological stimuli, which support and shape the human life. Of course, it is not suggested that its forms do not change in time and space and that they always and everywhere remain the same ('equal with one another'), regardless of the era, ethnic group, social strata and other circumstances. Thus, culturology accepts the view that cultural forms, events and phenomena align with the life, activity and characteristics of the human, of the society, civilization and history, i.e. they enter in a multitude of relations with phenomena other than culture itself.

The particularity of culturology, however, resides elsewhere. As it is, sciences such as anthropology, sociology, psychology, xenology, and the history of culture inscribe the latter into their own structures, which differ from it both ontologically and in terms of their qualities. They subjugate it and oftentimes entirely dissolve it within them. This is the mode of operation for anthropology of culture, sociology of culture and semiotics of culture. They define cultural factors in terms of - respectively - anthropological, sociological, psychological, semiotic ones, etc. One is thence unable to determine with precision what part is 'the cultural' in anthropology, sociology or semiotics of culture, as well as to what extent those elements are of independent, formative nature and to what extent they are dependent and subordinate only ${ }^{7}$

Culturology attempts to face the challenge posed by that situation. It operates on the assumption that cultural phenomena of their ontological essence belong to a capacious, internally diversified category of artifacts, and not to organic or inorganic nature. They are not exhausted in their functions or features by the laws of biology or physics. Meanwhile nature to some extent has to be reckoned with, for instance, within anthropology, which analyzes

7 Demarcation of that sort proves difficult due to the fact that culture is defined not only by the meanings ascribed to various artifacts, but also by its material components: e.g. marble, metal or wood in sculpture, paints in painting art, fabrics, leather, glass, plastic in collages, costumes and props in theatre, etc. In modern art they usually play the leading role, both in terms of construction and the 'spiritual' content. 
kinship, within psychology, which researches innate characteristic and unconditional reflexes, and within social sciences, which consider not only the organization and political system of the society, but also the influence of the existing natural conditions (geographical location, climate, natural resources) on the way of life of any given community.

Conversely, cultural phenomena are primarily determined by human characteristics, behavior and agency: the intellect, the acquired qualifications, applied technology, knowledge, existing models, the artistry of craft, customs and traditions, emotions, imagination, sensitivity. These are after all derivatives of the above. Concurrently, they are subject to social circulation, they are detached from their creators, users and consumers, becoming to some degree independent, they reflexively influence their creators or receivers. The circulation of that sort oftentimes changes, modifies or updates their original characteristics and purpose. Together with material carriers and meanings, it co-constitutes the reality of culture.

Contrary to the causally determined world of nature, culture remains within certain limits arbitrary (discretionary), conventional and 'flexible'. Its creations might be reproduced, they can be mobile, 'nomadic', exchangeable and replaceable 8 . Their fates are largely - though not on every occasion determined by choices, decisions, actions and reactions by the subjects of culture. They form inter-subjective and trans-cultural conventions, genre patterns and shape traditions embedded in a given environment, much like they subsequently fall form circulation and atrophy. They engage real culture-forming forces: the exiting individual, social and material - cultural potential ('assets'), including its symbolic aspect. They decide both on creation, reproduction and sustenance of certain cultural systems, forms and values, and of their modification, changes introduced to them, expansion, reduction, and abolishment. Hence, they influence the above-mentioned

8 The notion of mutability, replaceability or exchangeability of cultural elements is often at odds with the ethnocentric view of culture, which tends to underscore its folk roots, organic character, duration, particularity, its being unchangeable and irreplaceable. See: Kaschuba 1955. 
uninterrupted circulation of works, forms and values both within a single cultural area and between such fields, as well as in the universal scale?

These properties are decisive for ontological, qualitative and functional specificity of the cultural phenomena. They make it not only possible but requisite that they should be considered not only in the context and in relation to qualitatively different phenomena of being - human psyche, interpersonal relationships or behaviors, the society, history, nature - but also, to use the language of philosophy 'in and for itself', especially due to their particular ability to symbolize, archive and transfer meaning, as well as their expressive (incl. aesthetic) influence. It is worth stressing that such approach is a prerequisite for the very possibility of culturology - otherwise it would loose the distinctiveness in terms of its subject matter and theory and would end up aligning itself with particular sciences of culture.

At this point, one should differentiate between linguistic systems (e.g. speech) and semiotic ones (e.g. the International Code of Signals) specialized in transferring meaning and formulating messages and, on the other hand, all other objects primarily serving other purposes - such as production, consumption or military activity - which may also on some specific occasions perform sign (symbolic) functions, communicate meaning and have expressive effect. Such functions are performed in various cultures for instance by bread, sickle or a sword ${ }^{10}$. According to L.A. White (1959:

9 An example of such phenomenon may be seen in literature and the existence, as noted by Johann Wolfgang Goethe, of supra-national world literature (Weltliteratur).

10 In the chapter Symbol in the System of Culture Y. Lotman (2001: 103) defines symbol as 'a content which in its turn serves as expression level for another content, one which is a rule more highly valued in that culture'. In terms of expression and content, a symbol is embodied in a particular text of specified meanings and boundaries enabling one to recognize a specific symbol in the sign and textual context. Additional indicators of cultural symbols are: 1) inherent archaic components, as the memory contained in symbols tends to reach to the prehistoric times, 2) internal memory of symbols tends to be in principle older than its contemporary linguistic and textual environment (context), 3) due to their archaic and long-lasting character symbols are responsible for the continuity of culture, 4) their combinations define the identity of various cultures, although 5) some 
230-233), the ability of a given object to perform a symbolic function, whether linguistic, sign or communicative one, decides of its affiliation to a culture, though it does not rule out its other uses, say, as a working tool (sickle, hammer, hoe, seeder, scales, a pair of compasses, trowel, etc.), an object of consumption (bread, grain, the grape, fish, corn, apples, etc.) or pieces of armament (sword, bow, spear, machine gun, cannon, etc.). Neither does it eliminate the potential expressive (aesthetic) effect. Such multi-faceted and multipurpose character of artifacts originated in the culture of everyday life makes it different from those similar to the articulate language, which specialize in determining and transferring meanings.

Hence, culturology deals with the phenomena which - regardless of other practical applications they may have (as tools, food, clothing, decorations, etc.) - serve or are able to serve first of all symbolic functions, i.e. transfer meanings and messages, and, secondly, in that respect they constitute a separate class of internally interconnected artifacts, i.e. culture in a narrowed-down meaning of the word. The ability to express and transfer meaning, as well as to participate in human communication is what de facto separates in terms of substance, pragmatics and function the class of cultural phenomena - with their internal diversification - from nature, production, technology and consumption. The fundamental difference stems from the fact that signs and symbols indicate (mean) by their nature something different than themselves, whereas non-sign creations are in essence equal to themselves. They are granted the ontological status of a thing (res) and are subject to description and use, so to speak, in themselves.

The above makes apparent the need to identify other features of culture against the backdrop of extra-cultural entities, as well as in comparison with them, especially those ones which, although serving symbolic function, possess properties and functions not limited to creating, transferring and archiving meaning, as they also participate in such utilitarian, marketing or administrative spheres of human activity as production, consumption, distribution, trade, army, law, etc. It is beyond question that these spheres impart their influence upon cultural phenomena. They impact fields which, like the articulate language or other conventional sign systems,

symbols are subject to transcultural migration and a process of internationalization of sorts, oftentimes related to a change in meaning. 
serve primarily to express and transfer meaning. These borderline domains are also entailed by culturology - without them the resulting perception of culture would prove selective and limited to, say, artistic culture, and hence curtailed.

It should be particularly stressed that the selection procedure of the cultural components sensu stricto does not mean that they can be regarded as isolated, self-sustaining and independent items 'working on their own account,' without entering any 'misalliance' relations and mediations with organic and inorganic nature, the social environment and technology. Nor does it entail the lack of interactions and interdependencies. Those bonds, mediations, interactions and interdependencies constitute a fertile field for the above mentioned sciences of history, sociology, anthropology, psychology and ecology of culture - obviously, providing that research does not in turn replace cultural components with somatic, mental, existential, social, political or environmental ones.

The above problems are also a point of interest for the culture-oriented Geisteswissenschaften, practiced predominantly in Germany, which highlight foremost spiritual factors: moral, mental, ideological. At the opposite end of the spectrum, one could situate the cultural studies originated in Great Britain, on the whole materialistically driven, initiated by the works of the Birmingham School (Centre for Contemporary Cultural Studies), inspired by the works of Stuart Hall and Raymond Williams, the originator of the cultural materialism movement, as well as many scholars from other countries like: Germany (the Frankfurt School), France (Louis Althusser), Italy (Antonio Gramsci), USA (the New Historicism movement). Anyhow, the list does not exhaust the entire scope of the international expansion of cultural studies ${ }^{11}$.

Their importance for culturology is expressed particularly in the fact that they generally take up current and vital issues, beforehand frequently marginalized, from the fields of sociology of culture, cultural politics, ideology, power, hegemony, colonialism and post-colonialism, cultural

${ }^{11}$ Baßler (2003: 132-155) considers these movements as one conglomerate, extending it to also include Michel Foucault's 'discourse analysis', the notion of the 'thick description' originated by Clifford Geertz, Paul de Man's 'allegories of reading' and Stephen Greenblatt's 'poetics of culture'. 
identity, gender, emancipation movements, transgression. They concern transformations and shifts which change the image and the map of the postmodern contemporary culture 'undergoing the process of internationalization'. They study the methods of waging cultural manipulation by centers of power. By expanding the very notion of culture, the movement discussed goes beyond the framework of 'high', 'élite' or 'avant-garde' culture. At the same time, it takes into consideration a wide scope of the culture of everyday life and of the deprived strata of society, the issues engendered by cultural industry and the mass culture it produces, the popular culture, the operation of new media in that field (incl. television, the Internet, mobile telephony, video, advertising). In other words, it follows the current technological breakthroughs and examines their influence on cultural transmission and transformations. Moreover, it does not refrain from including the youth subcultures, the underground and the counter-culture. These researches, on the one hand, adapt and modify the notions of cultural science and culturology to suit their own purposes; on the other, however, they provide culturology with influential feedback. What is characteristic of them is that, as a rule, they situate cultural phenomena in the light of the contemporary civilizational and social transformations. They often display journalistic, whistle-blowing, critical attitudes.

The discussed issues of the interrelations between culture and the broadly understood 'non-culture' does not, as can be inferred from the preceding considerations, the main and direct subject matter of culturology, which instead strives to first of all express and establish what constitutes 'the culture in culture.' Also in that case, it avoids the substitution of cultural content with the issues of its material and technological carriers, as the misleading thesis by McLuhan that 'the medium is the message' would have it. It does not mean, however, that culturology turns a blind eye to or underestimates those technological or electronic mediators, as the distinctive feature of contemporary cultural symbolization and textualization is that ever more often they refer to those data storage media, although the latter when left to themselves and severed from the transmission of relevant content fall from cultural circulation and populate the domain (wasteland?) of deaf and mute things 'in-themselves'. 


\section{DELIMITATIONS OF CULTURE}

Undoubtedly, one of the aims of culturology is the delimitation of culture: the reflection on its scope and boundaries. On this matter an opinion has been established - and it cannot be denied that it is in some respects correct that culture was not only created by the species of homo sapiens, but also that it constitutes the species and is an expression thereof. Having culture at hand - which entails the ability to create, assimilate, accumulate and infuse it into various fields of both individual and social life as well as narrowly defined psyche and personality - distinctly differentiates homo sapiens from the world of things, plants and animals. However, the advancements in research along with the accelerating civilizational transformations have posed multiple questions regarding this traditional notion.

For the above view is complicated by observations and research which claim that 'culture-like' behaviors and forms, such as imitation, learning, adaptive behavior, issuing and reception of signals, signs or speech as well as partner and social communication are present not solely among humans, but also in the world of animals, especially among the eutheria ${ }^{12}$. Besides, there has been a long-standing dispute regarding whether and to what extent the cultural and culture-like behaviors in human and animal worlds are at all comparable with one another or parallel with respect to their structure, function and level of development. This question pertains to an important from the point of view of culturology issue, to wit, whether and to what degree culture is immersed in nature, to what extent it emerges from it and participates in it in one way or the other. One more crucial question is in turn whether it owes its existence and development solely to the human, homo sapiens, or whether it is in some proportion the result of a common, millions of years long evolution of life forms and species ${ }^{13}$.

12 Numerous instances of such cultural or quasi-cultural behaviors of animals and arguments for and against the existence of culture in that domain are provided by Laland, Galef 2009: 1-18.

13 A hypothesis of an affinity between the world of humans and animals and their ability to communicate was postulated from biblical and Christian standpoint by Cyprian Norwid in his polemics against the $19^{\text {th }}$ century naturalists and evolutionists to which he devoted a late essay of his, Ostatnia z bajek (1882). 
The attitude of culture towards the 'reified', mechanical and automatized world of technology also undergoes reevaluation. H. Böhme and K. Scherpe (1996:14-15) managed to aptly highlight the issue:

The interfusion of cultural processes with technological strategies, devices, media and sets renders culture (cultures) to a growing degree as a technological conglomerate, which in light of the tasks undertaken by science no longer separates natural sciences from 'sciences of spirit' (Geisteswissenschaften), understanding from explanation (Wilhelm Dilthey, Stephen Toulmin, Georg Heinrich von Wright) nor literary from technical intelligence (C.P. Snow), according to their method of description. After all, traditional 'sciences of spirit' themselves largely resort to explanatory and technical procedures - for instance in the field of media discourses and theories - causing the above distinctions to lose their validity. Hence, the neoKantian, fundamental definitions of Geisteswissenschaften, originated at the turn of the $20^{\text {th }}$ century, favoring bipolar approach, seem to cease their viability as theoretical reference points at the beginning of $21^{\text {st }}$ century ${ }^{14}$.

Setting aside the complex and controversial theory of evolution and the consequences thereof, it can be assumed that the differences between human and animal worlds transpire in several ways. They find a striking expression in the fact that all the respective works and fields of culture, a notion pertaining mainly to historical eras when writing was used, unfold as an exercise of will, intentions, consciousness, decisions and skills of individuals or a joint effort by groups of social or ethnic communities. Additionally, the difference lies in the historical character of culture, a feature conceptualized and articulated through various cultural behaviors. It is an inherent component of the early-modern and modern cultures and it impinges on cultural choices and activity.

Other illustrations of cultural differences between the two worlds are provided by literature, art, architecture, technology, agriculture, science. Many works of art, literature, philosophy or science, as well as series of inventions, novel applications and discoveries are of individual, particular, personal and genuine character. They are directly motivated by the initiative and exploratory activity of individual persons and only indirectly influenced

14 The spread of technological means in culture was the reason why 'media studies' emerged as a particular, distinct discipline. 
by repetitive patterns of behavior and group or generic models. Meanwhile other phenomena, such as agriculture, transportation, architecture, urban planning and industry regarded as cultural and civilizational undertaking display the scale, spectacular character, complexity and quality unmatched when compared with the animal kingdom. They require collective coordination, organization of tasks and complex machines, which either reflect or shape the advanced work culture of humans.

The above grounds make it rather difficult to speak of complete equivalence of animal and human cultures. Instead, one should differentiate the elementary and precisely defined micro- or mini-cultures of the animal world from the developed and intricate human culture. At this point, the differences of scale, significance and level of accomplishment involve a leap in the level of complexity, quality and functionality. Therefore, in lieu of modernist and post-modernists attempts at an utopia of 'humanizing' or 'enculturating' the animal kingdom, the object of reflection (and care!) should be the rather frequent naturalist cases and images of 'theriomorphism' of individual humans and human societies, which do have culture at their disposal. These make one aware of the inconsistencies in the constructive, positive inculturation of human - in the saturation of its 'bios' with humanistic ideals and norms - and are a testament to the existence of degenerate, detrimental versions and variants of culture.

However, one should not lose sight of the fact that some cultural phenomena are a creation of anonymous forces and processes, operating either randomly, according to the 'blind watchmaker' principle, or imperceptibly transmitted and assimilated, lastly it may function at the level of the unconscious or the individual or collective subconscious (see: Bainbridge et al. 2007). Hence, culture is pervaded by works, norms and rituals of which we do not know where, when and by whom they had been created (folklore, proverbs, myths, fables and legends, customs, rites). They provide grounds for the understating of culture as something normative, impersonal and anonymous, as well as of its regulative, systemic mode of operation, which bends all the individual endeavors and behaviors to its systematic regulation $s^{15}$. Romantic notions of culture as the domain of freedom (improvisation, invention and

15 Such approaches seem typical for the Soviet and Russian culturology of the 1960s and 1970s. 
spontaneity) find their counterpoint here in an opposite position assuming its subjugation to norms, coercions and necessities, providing grounds for the Freudian conception of culture as repression and a 'source of suffering'.

The anonymity and the unknown origin of various artifacts, norms, taboos and rituals are partly explained by the fact that some of them date back to, as reported by archeology, prehistoric, preliterate Paleo- and Neolithic periods (or earlier), the people of which could not have been aware of the concepts such as authorship, an individual, individualism or originality, established relatively late within the history and the civilization. It is also doubtful whether those ages saw people capable of cultural and meta-cultural thought. However, the temporal distance makes the prehistoric and preliterate creators of tools, arms, ornaments and pendants, elements of attire, cave paintings (petroglyphs) and cultural figurines (such as the Venus of Tan-Tan discovered in Morocco or the Venus of Berekhat Ram discovered in the Golan Heights ${ }^{16}$ ) by definition remain just like the Cro-Magnon Man unrecognizable and anonymous. Many archeological discoveries suggest however that it was them who gradually created conditions enabling the relatively young for only dating several thousand years back - historical societies to come into being, already equipped with a relatively well-developed resources of artifacts and inventions. The latter comprised for instance the division of labor and duties between males and females, the organization of collective activities, the production of clothes, artistic output, elements of agriculture, as well as the establishment or construction of permanent settlements, etc. (Mears 2015: 82).

It should also be considered that a proportion of cultural behavior with time undergoes an imperceptible process of naturalization, its conventional origin becoming obliterated and as a result impossible to reconstruct and decipher. The same is true of the cultural collective memory ever changing its direction and center of pressure. One should therefore acknowledge the hypothetical existence of various deep-seated, 'fossil' sources of culture, still awaiting discovery and identification. From that point of view, the delimitation of culture would be a process inscribed into the history

16 Incidentally, scholars are in a dispute whether the above mentioned figurines are indeed man-made artifacts or whether they received their anthropomorphic forms by way of random natural processes. 
of mankind, pertaining not only to the existing limits, as established once and for all, but one that must also reckon with the prospect of delineating new borderlands. It follows from observation of how the various cultures function. They benefit both from the rules of reproduction (a repetition of established patterns and techniques), as well as of production (creativity), which takes into account novel ideas and needs, inventions, hitherto unheard of skills, sources of energy, materials and the changing conditions.

Such circumstances make one realize that the lack or scarcity of information on the creators and users of archaic artifacts, their context, techniques and the methods of their production and their actual functions in primary communities do by no means indicate that they came out of thin air. Nor does it prove that such prehistoric creators, users or communities never existed in the first place. The very same considerations apply to the primordial foregone processes, definitively no longer active. Therefore, our ignorance or blank spots we face are no justification for the categorical proposition that culture is characterized by anonymity, the 'everlasting archetypes', the inertia of systemic coercion or unconscious pressures of injuries resulting in hidden and impossible to overcome traumas.

The delimitation is rendered still more complex by the polar opposites of its inherent dispositions. They entail, on the one hand, the ability of a given culture to assimilate the acquisitions derived from other cultures, while on the other, conversely, the capability to resist the promoted or imposed models, behaviors, artifacts, institutions and habits. The latter are usually offered with the view of replacing the local forms with foreign ones, outdated customs with modern ones, the rural with the urban, etc. It is noteworthy that the resistance against the imposed culture oftentimes finds its paradoxical expression in an inflated affirmation of the familiar heritage, even if the latter does suffer from evident shortcomings and proves dysfunctional. For an illustration, let us turn to Sarmatizm in its conflict against the enlightened 'Frenchness' and more broadly 'foreignness'. It is impossible however to ascribe always the same tendencies to a given culture and at the same time to provide general diagnoses on the basis of current observations. It may just as well display reluctance to innovate and a tendency for stagnation, as be characterized by openness, receptivity and flexibility. Such potential is inherent in its internal instrumentarium and repertoire, though it is its adherents who decide of their use. 
That results in a persuasion that culture as such cannot be fully identified neither with individual nor collective psychology and ethnos; neither social status, nor political constitution. For it is an acquired value whose state (use) depends on particular external circumstances, needs, living conditions or social standing as well as deep-rooted habits of its bearers. The very same culture may be characteristic for various social strata and, contrariwise, the representatives of the same stratum may be representatives of different cultures.

It leads to the conclusion that the relation between culture and its human background, whether ethnic or social, may be dynamic. The culture which undergoes internal transformations and partakes in interaction with other cultures reacts to shifts and changes occurring in that background and at times initiates them itself. That in turn brings to our attention the fact that the 'unity' of universal culture is a rather theoretical and hypothetical than a descriptive and referential notion. At the foundation of the suggested unity, there is an undeniably real multiplicity and diversity of cultures ${ }^{17}$. The striving to coordinate these contrary statements reflects the specific theoretical stance of culturology: on the one hand, an inherent in it tendency to generalize and find the underlying laws connected, on the other, the respect for the emerging and diverse cultural reality.

At this juncture, however, there is an important reservation to make regarding the issue of diversity. Indeed, from the fact that there is a multiplicity of cultures it does not follow that they are unequal. The idea of the unity of culture postulated as the foundation of culturology enters into polemics against the discriminating and restrictive division of cultures into ones higher and lower, better and worse, sophisticated and barbaric, etc. Such

17 Such diversity was explained by Claude Lévi-Strauss by the fact that human nature is defined by what is universal in nature, whereas the human behavior on the other hand is governed by various particular and personal rules, which are an effect of the existence of diverse cultures. These cause human attitudes, behaviors and choices to diverge in terms of nutrition (cuisine), clothing, expression of emotions, morality, the understanding of good and bad, the perception and evaluation of others, varying interpretation of events, etc. What distinguishes humans from nature is therefore the 'cultural variability' (la variabilité culturelle) they display; see: Charbonnier 1969. 
attitudes engender various racist practices, ethnocentrism and nationalism ${ }^{18}$. Therefore, while opposing such views, culturology posits existence of many divergent, but concurrently equal cultures, which interact with each other in various ways, interfuse one another and exchange models and values.

The principle of diversity and equality seems to be contradicted by the position which emphasizes the phenomena of long-lasting inheritance of the very same culture by ethnic, social or religious communities. The latter stance is accompanied by a suggestion that culture therefore defines the 'lasting' or even 'immutable' features of a given community. However, the issue overlooked here is the fact that the process of inheriting does not involve mechanical reproduction and immobilization. For it entails incessant reevaluations and transformations, oftentimes on the micro-scale and hardly perceptible. Additionally, these often occur under the influence of their environment: perfusion, transfers and impact of other societies and the cultures thereof. That is why the claims of 'inherited consistency' and 'immutability' either of a given culture or of a given community narrow down the historical horizon to a complete and fixed past, at the same time ignoring the open and surprise-ridden future. The words of the poet: 'Oh! Incomplete still the labor of History' (Norwid 1971: 19) should sound as a warning and a lesson for all those who rashly identify culture with the process of inheritance.

The specificity of the respective cultures stems from the fact that each constitutes a composition of varied elements, while the diversified shape of its entirety comprises all the essentially different respective cultures. Such state of affairs pervades both synchrony and diachrony. It is fostered by the internal transformation and diversification of cultures, the replacement of those exiting the scene of history by those entering it, the super-session of the defeated with

${ }_{18}$ In its essence, nationalism treats its own society and its own culture as an unsurpassed model for other ones and perceives any deviation from that model as an indication of inferiority. In fact, such community and the culture thereof make claims to and herald their superiority on a meager basis of an arbitrary criterion, no more reliable than similar criteria posited by other communities and cultures. The 'superiority' of a culture advertising itself as such remains improvable. Which in turn means that ethnocentrism is devoid of any real foundation and ends up reduced to a form of collective solipsism and pretension. 
the dominant, the traditional with the modern, the classical with the hybrid. The emergence and sustenance of diversity is supported in an equal measure by: the conservation of tradition, the acts of borrowings, the inter-cultural exchange and dialogue. For the prerequisite for genuine diversity is any 'difference' and 'otherness', as these always counteract entropy. For instance, it benefited on the macro-scale from the processes of supplanting of polytheism by monotheism, of the poeticized ethos of chivalry by the trite bourgeois bonds and affinities, of Indian wigwams by brick-built mansions of plantation owners, of carriages by cars, of fire torches by kerosene lamps, of the water energy by the atomic energy, etc.

In that sense, neither individuals nor communities are determined by a unified and long-lasting type of culture ascribed to them and unaffected by the transformations of the existing relationships or circumstances. For even the existence of an increased systemic control (e.g. in the form of an explicit or covert censorship) does not entirely rule out the possibility of introducing to such cultural system be it only limited innovations, of achieving some reshuffling and reevaluation as well as complementing it with borrowings. History proves that even the most isolated political systems (such as the totalitarian states) do prove to be in some areas permeable and porous. A researcher of an early Chinese intellectual influence in Europe thus characterized the issue:

(...) there has never been an autonomous civilization in history, which proved capable of providing continuous development inside a framework of political or economical autarchy. (...) [T] o assure an extensive, successful era of peace and prosperity, civilizations have to draw on 'useful knowledge' from other centers of civilization.

In nature, as in history, there can be no knowledge without contact human knowledge is continuously reborn by the forces of contact, ever changing, evolving towards ever more complexity (Gerlach 2005: 3).

\section{ACCELERATION, LITERACY, MULTICULTURALISM, CULTURALISM}

The crux of the matter is however that cultures accumulate the acquisitions of the past and that at their sources they have - albeit not always perceptible for the naked eye - the previously shaped and adapted experiences, skills 
and traditions which, though somewhat modified and adjusted to the everchanging conditions, at the same time resist the arbitrary and voluntary innovations. It can be rightly assumed that in the global and historical scale - the observation on such scale being enabled by the contemporary civilizational processes, especially the intense development of exchange, communication and spread of information networks - culture accelerates itself. It assimilates the heritage of the past eras, concurrently liberating itself from their determining influence. Here, the components of inheritance, transmission, as well as innovation and novel initiatives compete against one another and mutually interfuse. The continuity, the recycling and rewriting, the interaction, the acts of breaking out and the cultural turns, as illustrated by the history of culture, serve to shape its contemporary accelerated dynamics which bursts the existing frameworks and models.

Consequently, of interest for culturology are not only the specificity, markers and inter-connections of cultural phenomena, but also - as already mentioned in another context - their becoming and transformations. A version of culturology that would focus on by definition static systemic relations and ignore the changes would soon prove anachronistic and useless.

Still, it cannot be denied that our age also witnesses opinions which underscore the idiomatic, incomparable and closed character of the respective cultures, especially those geographically distant, for a long time bereft of interaction and common history, wide-scale trade relations, exchange and vivid links to cultures of other continents. The issue pointed out here is the distance and distinctiveness of cultural models and traditions between the lay rationalistic culture of the West (of Europe) and the notions, imagery and beliefs of the Far East. How to align then, say, the Bible or the Western lay scientific thought with Shintoism, Taoism, Buddhism or Hinduism? And vice versa: how to acquaint the West for instance with the Chinese art of organizing space of feng shui or the Taoistic philosophy and ethics known as $w u$ wei? ${ }^{19}$

Were we to assume, as some contemporary scholars drawing from the ideas of Thomas Kuhn and Paul Feyerabend postulate, a fundamental incommensurability of cultures (cultural systems) (Alarcón, Anthropology...) - hence

19 The principles and application of $w u$ wei are discussed in: Singerland 2003. 
their internal impermeability, untranslatability, closure, a 'walling-up' of sorts - they would become for their carriers hurdles obstructing both communication and exchange with external environment as well as their own flexibility and progress. It would favor ineffectual limitations. ${ }^{20}$ In order to avoid such consequences, a given culture - in fact operating so to speak in its own interest - has to (or ought to) consider and emphasize in its working the elements of initiative, innovation and freedom as well as participate in the cultural exchange and as a result directly or covertly accept the inter-cultural transfers and borrowings. Culturology posits such processes as a prerequisite and a factor in the development of culture. Such directed actions have become one of the canons of cultural politics although it is worth noting that often they must face resistance and limitations. The latter are engendered by the influx of bearers of a foreign ('alien') culture which poses a threat to the stabilized position of the local culture, accustomed to its own dominance.

A challenge to the theory of incommensurability and untranslatability of cultures comes in the form of the practice of cultural literacy, stimulated by intercultural migrations and contacts. In its extended understanding such 'illiteracy' refers not only to the articulate language and literature, but also to the entire field of a given culture, including artifacts as well as behaviors,

20 I quote here in extenso a high-profile and often cited argument by Hilary Putnam (1981: 114-115) presented to oppose the theses of incommensurability: 'The incommensurability thesis is the thesis that terms used in another culture, say, the term "temperature " as used by a seventeenth-century scientist, cannot be equated in meaning or reference with any terms or expressions we possess. As Kuhn puts it, scientists with different paradigms inhabit »different worlds«. (...) The rejoinder this time is that if this thesis were really true then we could not translate other languages - or even past stages of our own language - at all. And if we cannot interpret organisms' noises at all, then we have no grounds for regarding them as thinkers, speakers, or even persons. In short, if Feyerabend (and Kuhn at his most incommensurable) were right, then members of other cultures, including seventeenth-century scientists, would be conceptualizable by us only as animals producing responses to stimuli (including noises that curiously resemble English or Italian). To tell us that Galileo had »incommensurable« notions and then to go on to describe them at length is totally incoherent'. 
customs and rituals ${ }^{21}$. It reveals the intellectual, linguistic, semiotic, symbolic and textual (discursive) potential inherent in the latter. As an analogy to linguistic and literary literacy, which consist in the ability to read, write and communicate with the use of one's command of the alphabet, the vocabulary and the rules of grammar - and from there in the skill of creating and receiving messages in a foreign language - cultural literacy, at times erroneously seen as erudition, involves the mastery of the code, rules and conventions of a foreign culture and the ability to enter into efficient communication with its bearers and representatives. It does also involve the awareness of the preferred lifestyle thereof, the orientation within 'the great narratives' and anecdotes of the foreign culture, its forms of entertainment, modes of expression, idioms, idiosyncrasies, cultural and historical allusions, topography, etc. It applies both to its refined expression ('high culture'), as well as to the everyday behaviors (greetings, etiquette, clothing, meals, collective leisure activities, understanding of symbols, etc.). The effect of that sort of literacy can therefore be a shaping of a universe of discourse common for diverse cultures, which would blur the boundaries and seemingly insuperable barriers to communication.

Cultural literacy is a consequence of multiculturalism and the increasing mutual intercultural influence (interculturalism), and at the same time it is a catalyst for the development of both these processes. Their essence being contacts, interference (mixing) and interactions between bearers of diverse cultures, they intertwine the very cultures themselves. Processes of this kind - not always desirable from the point of view of ethnocentrism and the ideals of a national state - foster both the opening to foreign cultures and the assimilation of their codes as well as enable the transfer of culture's own codes and wielding the influence on others in selected fields. These three phenomena - cultural literacy, multiculturalism and the interaction of cultures - doubtless reflect the momentous cultural processes of today

${ }^{21}$ James Gee (1991) defines cultural literacy as an ability to function within an environment with the use of discourses which bring together 'language, thought and action'. The concept was further developed by William T. Fagan (1996). He framed literacy in terms of cultural competence enabling communication and behavioral passage from the primary cultural context to extensive ones. 
which modify many traditional, often outdated, notions of culture and therefore cannot be set aside and excluded from the perspective of culturology.

Thus cultural literacy, rooted in multicultural society and interaction of cultures, stimulates a deeper, authentic intercourse with cultures different to one's own, concurrently enabling one to perceive one's own culture from the position of 'being out of it' and seeing its reflections in the mirrors of other cultures - i.e. from the perspective of someone using a different cultural code (codes), who perceives and models reality (and potentially) their own existence according to different rules. This provides an opportunity to improve and reevaluate the respective aspects of one's culture, to become aware of its potential inconsistencies and to endeavor to amend those $\mathrm{e}^{22}$. Such attitude of otherness (and a kind of alienation) from oneself could at first glance seem utopian and impossible to perform; however, it is in fact a necessary condition for cultural transgression, for stepping out of an ethnolinguistic monoculture and entering into a dialogue with the other. It provides an opportunity to replenish and diversify a given cultural repertoire.

${ }^{22}$ One model for a theoretical stance and strategy of the sort remains the existential and epistemic-ontological idea of 'outsidedness' or 'outsideness' (Rus. wnienachodmiost) envisaged in the early works by Mikhail Bakhtin. It consists in revealing the fundamental cognitive differences in perceiving oneself and the other. The difference lies in the fact that an individual (or a collective subject) is unable to cognitively define themselves from the outside as comprehensively as they could see the other. It is rendered impossible by the position of the eye which can see what is 'in front' or 'to the side' of it, but not what is 'at the back' or 'behind it'. Therefore, such seeing is characterized by a certain kind of 'surplus of seeing' with regard to the other, with a simultaneous 'insufficiency' of seeing with regard to oneself. Such insufficiency of seeing oneself from the outside and the surplus of seeing the other is in turn reflected in the surplus of the internal, fluid, contour-less self-observation (introspection) of a given subject and the insufficiency of knowledge of the internal reality of the other. A similar cognitive situation enables the subject to relatively delve into the other through transgression and return to oneself with the acquired knowledge of the other and of oneself in relation to the other - without the necessity to resign from one's own perspective and worldview. Such return is a prerequisite of a constructive dialogue with the other and one that can expand the horizons (field of view, circle of values) of both sides. See: Obukhova 2013: 35-46. 
The above metamorphosis also serves to create common ground between different cultures and facilitates the exchange between them. Culturology confronts the negative and perplexing thesis of incommensurability, incompatibility and untranslatability of the respective cultures with an alternative image - founded upon the comparative research of history of their chronic inconclusiveness, insufficiency and incompleteness, obliging them to enter into exchange with their cultural surrounding. The example (and the model) of literary literacy, a feature narrower than cultural literacy, proves particularly useful in that field. It makes us aware that in the modern-day civilization, literature created possibly in any known language becomes an element in the process of being translated to other languages. Thus it is a subject to a double transgression. The manner in which it occurs is through translation and assimilation of works representing foreign languages and literature which could potentially originate or perpetuate some changes in the local literature, at any rate expanding its view of the reality. Another form of transgression involves on the other hand translating local literature into foreign languages. A given literature crosses out of the boundaries of its familiar ethnic language and literary system and blends into new surroundings. As an example, one could look at the international reception of the Shakespearean oeuvre, while at present - a similar reception of the Nobel Prize laureates. In both these cases, transgression and translation stimulate the literary process. In such case the self-sufficiency, isolation and closure of literature (or culture) within itself - regardless of whether it was forced or steered from external instances (such as the authorities, ideology, religion or tradition), or whether it was the result of an inflated self-esteem - would amount to a stasis and an impasse in literature. In this instance, the parallelism with culture seems self-explanatory - on condition that the notion of literary translation is complemented by the concepts of inter-artistic and intercultural (inter-semiotic) translation (Faiq 2004: 3).

At the opposing pole to the view of a selective, closed and impermeable for diverse values Kulturkreis, one finds the concept of the so-called culturalism. The latter proclaims omniperfusion and omnipresence of culture throughout all aspects of life, thereby questioning our ability to take a stance external and distanced from it. It undermines the ability of an individual or collective subject - whether ethnic or social - to perform an independent and standalone evaluation thereof, further still: to chose, modify and shape 
aspects of reality according to criteria other than those inherent in it. It negates the possibility of emergence of attitudes and preferences independent from it or the possibility of taking initiative and introducing innovation. It rules out in advance the opposition and resistance to the irresistible and pressuring itself both from inside and outside cultural Wille zur Macht.

What is posited here therefore is that cultural phenomena stem from other cultural phenomena ('of their own accord') and that they leave a mark upon every expression of human life and activity. According to expansive culturalism, the very cognition of culture is culture-dependent (a clear indication of an occurrence of a circularity in the concepts of culturology). Its potent reach encompasses religion, science, politics and economy. Culturalism distinguishes and underscores in all these fields what is in line with culture, while at the same time it blurs and ignores the instances of diversity and variety. It openly or covertly absolutizes the principle of cultural abiogenesis (generatio spontanea).

Such notion leaves the individual, society and culture in a shrill opposition to nature. It sees the latter as an ever less influential factor and of ever less influence on cultural and civilizational spheres. At the same time, the idea points to the progressive removal of nature and the irreversible alienation of human beings and communities from it. The concept of the human as a biological part of nature - including the Rousseauian utopia of the noble savage - the adherents of culturalism replace with an anthropological concept according to which the human is the creator and bearer of culture, yet entirely defined by it and constituting an inseparable part thereof. Nature, in turn, was assigned the properties of a substrate, refined and crafted according to the resulting needs and models, subsequently transformed into artifacts introduced into cultural circulation, which in turn delineates the boundaries, framework and space for individual and social existence.

Culturalism also sanctioned notions which see culture as a system of signs, symbols, meaning and texts of all sorts. It identified it as the 'semiosphere'. It assigned primacy to specific systems (and sub-systems) of signs and complexes of cultural texts both over natural and social phenomena $^{23}$. These determined the methods of identification and self-

23 The notion of culture as a system of signs and processes of communication is at times extended out of the anthropic sphere to also cover the world of animals, 
-identification of the members of communities together with their tradition and mutual communication. They enabled contacts with other communities and co-created the models of the world which allowed for interpreting the surrounding reality and navigating through it.

It is worth emphasizing that the semiotics of culture was formulated by scholars from different countries, to mention only Ernst Cassirer, the author of Philosophie der Symbolischen Formen (in three volumes, 1923-1929), Claude Lévi-Strauss, the originator of structural anthropology and the author of Anthropologie structurale (1958) and Yuri Lotman, the author of a collection of essays Cтатьи по типологии культурь: Материальк к курсу теории литературь (1970). The thought of the kind was entertained and developed - predominantly in an American context - by Clifford J. Geertz in his The Interpretation of Cultures (1973), a compilation of his earlier essays and dissertations. William H. Sewell (1991: 51) thus generalized the discussed position:

What all of these approaches had in common was an insistence on the systematic nature of cultural meaning and the autonomy of symbol systems - their distinctness from and irreducibility to other features of social life. They all abstracted a realm of pure signification out from the complex messiness of social life and specified its internal coherence and deep logic. Their practice of cultural analysis consequently tended to be more or less synchronic and formalist.

Such views however do not seem to endure the contemporary criticism. By accentuating the uniform character and coherence of the system, on the one hand, they isolate and emancipate culture, relieving it of its historical and social contexts, liberating it not only from external circumstances, tensions and influences, but also from its internal irregularities and transformations. As a result, they purify it from heterogeneous additions, artificially simplifying and standardizing it. Such was the spirit of the advancements made by the Tartu-Moscow Semiotic School. Culture - wrote Yuri Lotman and Boris Uspensky (1978: 211) in the resonating style of the 1970s - 'is never a universal set, but always a subset organized in a specific manner.

plants and machines, and according to Romantics even the realm of ghosts and specters. 
Culture never encompasses everything, but forms instead a marked-off sphere. Culture is understood only as a section, a closed-off [! - E.K.] area against the background of nonculture'. What is symptomatic of his view is the undifferentiated and negative notion of 'nonculture'.

On the other hand, the concepts which regard culture as an impermeable 'closed system' identify it implicite with reproduction of the existing artifacts, norms, models and values. Thus they muddle they definition of culture into a regressus ad infinitum. Their stance is contradicted, however, by the empirical diversity, changeability and creative (innovative) character of the respective cultural phenomena, oeuvres, forms and processes. Therefore, Doris Bachmann-Medick (2003: 102) not without a reason observed that 'culturalism entails a hyposthasis of the cultural, ignoring the issues of power, social and material dynamics, politics and economy'.

To sum up, looking at these issues from the point of view of culturology, it is impossible to identify culture solely with transmission (duration), nor with its volatile changeability of forms; nor still with a reproduction of ready-made models or with rash creation of novelties. For it is characterized by both: duration and changeability, reproduction and creativity. Rarely confined in a closed systemic order, it incorporates and adapts elements from outside its familiar environment. It additionally performs recycling of the outdated and worn-out forms. Its variations and ramifications ('subsystems') are characterized by relative translatability through signs, symbols and meanings. It allows for enclaves of idiolect and separatedness, which in turn cultivate the 'secret' nature of signs and forms, their esotericism, 'the darkness of speech' or the breaking of the norms ${ }^{24}$.

Nevertheless, the above formulation does not fully reflect the manner of operation ('the life') of culture. Its affinity for hegemony, immobilization, systematization, uniformization, codification and hierarchization of values and models (for culture is a powerful weapon of power, of instilling pressure upon consciousness, it is a tool for controlling discourses and 'ruling people's

24 The issues related to esotericism are studied i.a. by the Paris chair of Histoire de l'ésotérisme occidental on the Sorbonne (currently a part of the École pratique des hautes études), Warburg Institute in London, Center for History of Hermetic Philosophy and Related Currents at the University of Amsterdam and Exeter Centre for the Study of Esotericism (EXESESO). 
souls and hearts') is counterbalanced by the polyphony, diversity and dialogue polarization. The clash of that sort was suggestively illustrated by Mikhail Bakhtin in his Rabelais and Folk Culture of the Middle Ages and Renaissance (1965). He shows there the historical conflict between the carnival culture of laughter and grotesque against the official culture cultivating the serious and abstract idealization. A contemporary image of these tense relations of polarized cultures (civilizations) was given in a journalistic - and criticized for over-simplifications - book by Samuel Hutington The Clash of Civilizations and the Remaking of World Order (1996). While foreseeing the end of the age of ideology, the American political theorist decided that the bone of contention at the turn of the $21^{\text {st }}$ century has become the irreconcilable cultural and religious conflict. In that respect, culture engenders sorts of complex, multilayered, volatile, cultural coincidentia oppositorum expressed by various circles ('subsystems'). In untangling and specifying of that notion lies one of the crucial tasks culturology faces.

A significant issue from the perspective of culturology is therefore that culture is produced by way of anthropogenesis. Shaped by man, it reflexively influences both its creators and their activity, as well as the surrounding world of civilization and nature. On the one hand, it is subject to internalization, it forms the personality, psyche and behavior of individuals. On the other, it influences interpersonal relationships and regulates their collective life. Its forms, once constituted and released into circulation, garner a social quality. They become a common good of sorts. They undergo objectification, emancipation, reification and naturalization. They are deprived of their oftentimes personal bond with their creators, inventors and legislators. They become anonymous and impersonal. They frequently turn into both binding and temporary 'taboos' and 'intransgressible norms'. However, it would prove hard indeed to find among the latter any that in the long run could successfully withhold the pressure of transformations and the relativizing influence of time. 


\section{Bibliography}

Joaquín Jareño Alarcón, Anthropology, Indeterminacy and Incommensurability, http://hottopos.com/convenit6/jareno.htm.

Moritz Baßler (2003), New Historicism, Cultural Materialism und Cultural Studies, [in:] Konzepte der Kulturwissenschaften. Theoretische Grundlagen - AnsätzePerspektiven, ed. A. Nünning, V. Nünning, Stuttgart: J.B. Metzler.

Doris Bachmann-Medick (2003), Kulturanthropologie, [in:] Konzepte der Kulturwissenschaften. Theoretische Grundlagen - Ansätze - Perspektiven, ed. A. Nünning, V. Nünning, Stuttgart: J.B. Metzler.

Caroline Bainbridge, Susannah Radstone, Michael Rustin, Candida Yates ed. (2007), Culture and the Unconscious, London: Palgrave Macmillan.

Hartmut Böhme, Klaus Scherpe (1996), Zur Einführung, [in:] Literatur und Kulturwissenschaft, ed. H. Böhme, K. Scherpe, Hamburg: Rowohlt Tb.

Robert L. Carneiro (2003), Leslie A. White, [in:] Totems and Teachers: Key Figures in the History of Anthropology, ed. Sydel Silverman, Walnut Creek: AltaMira Press.

Georges Charbonnier (1969), Entretiens avec Claude Lévi-Strauss, Paris: Les Belles Lettres.

Giennadi V. Diakonov (2006), Dialogijnaya koncepciya estetiki i literaturovedeniya M.M. Bakhtina, „Social'naya Psikhologiya”, No. 6.

William T. Fagan (1996), Literacy and Cultural Thoughtfulness: the Power and Helplessness within and beyond Cultural Boundaries, https://files.eric.ed.gov/ fulltext/ED416309.pdf.

Said Faiq (2004), The Discourse of Intercultural Translation, „Intercultural Communication Studies", Vol. XIII.

James Gee (1991), What is Literacy?, [in:] Rewriting Literacy: Culture and the Discourse of the Other, ed. C. Mitchell, K. Weiler, New York: Praeger.

Christian Gerlach (2013), Wu-Wei in Europe. A study of Eurasian economic thought, London 2005. Wolfgang Kaschuba, Anmerkungen zum Gesellschaftsvergleich aus ethnologischer Perspektive, http://edoc.hu-berlin.de/oa/bookchapters/ resf43HGISZo/ PDF/23uDV5SvKdUoc.pdf.

Stephen Greenblatt (1987), Towards a Poetics of Culture, „Southern Review”, Vol. 20, No. 1.

Wolfgang Kaschuba (1995), Kulturalismus. Vom Verschwinden des Sozialen im Gesellschaftlichen Diskurs, [in:] idem, Kulturen - Identitäten - Diskurse. Perspektiven Europäischer Ethnologie, Berlin: Akademie Verlag. 
Alfred L. Kroeber, Clyde Kluckhohn (1952), Culture. A Critical Review of Concepts and Definitions, Cambridge: The Museum.

Adam Kuper (1999), Culture. The Anthropogist's Account, Cambridge (Mass): Harvard University Press.

Kevin N. Laland, Bennett G. Galef ed. (2009), The Question of Animal Culture, Cambridge (Mass): Harvard University Press.

Yuri M. Lotman, Boris A. Uspensky (1978), On the Semiotic Mechanism of Culture, trans. G. Mihaychuk, „New Literary History”, Vol. 9, No. 2.

Yuri M. Lotman (2001), Universe of the Mind. A Semiotic Theory of Culture, transl. A. Shukman, London - New York: I.B. Tauris Publishers.

Yuri M. Lotman (2009), Culture and Explosion, trans. W. Clark, Berlin - New York: Mouton de Gruyter.

John A. Mears (2015), Integrating Prehistory into the Study Humanity's Common Past, [in:] Teaching World History: A Resource Book, ed. H. Roupp, London: Routledge.

Michael Minkov, Geert Hofstede (2013), Cross-Cultural Analysis. The Science and Art of Comparing the World's Modern Societies and Their Cultures, Los Angeles - London - New Delhi - Singapore - Washington (DC): Sage.

Claus-Michael Ort, Kulturbegriffe und Kulturtheorie, [in:] Konzepte der Kulturwissenschaften. Theoretische Grundlagen - Ansätze - Perspektiven, ed. A. Nünning, V. Nünning, Stuttgart: J.B. Metzler.

Cyprian K. Norwid (1971), Pisma wszystkie, Vol. 2, Warszawa: PIW.

Tatiana M. Obukhova (2013), „Wniekhamodimost” $w$ dialogie kultur (po rabotam M.M. Bakhtina), [in:] Jaziki. Kultury. Pierievod. Materialy miezdunarodnogo nauczno-prakticheskogo foruma, Moscow: Izdatel'stvo Moskovskogo Universiteta.

Hilary Putnam (1981), Reason, Truth and History, Cambridge: Cambridge University Press.

William H. Sewell (1999), The Concepts of Culture, [in:] Beyond the Cultural Turn.

New Directions in the Study of Society and Culture, ed. V.E. Bonnell, L. Hunt, Berkeley: University of California Press.

Edward G. Singerland (2003), Effortless Action: Wu-wei as Conceptual Metaphor and Spiritual Ideal in Early China, Oxford: Oxford University Press.

Mark Terkessidis (2010), Interkultur, Berlin: Suhrkamp Verlag.

Leslie L. White (1959), The Concept of Culture, „American Anthropologist”, Vol. 61, No. 2. 


\section{Summary}

Culturology is a distinct reflection on culture that emerged in the second half of the twentieth century, whereas the so-called cultural turn in the humanities (the turn that became aware of its cultural background and foundation) became the impetus for its development. The article tries to clarify what the term in question entails, what is the subject of its research, what kind of theoretical assumptions it makes in relation to its subject and what specific learning goals it faces. One of the key questions of culturology concerns culture, it asks about its limits, about the variance of its forms in space and time, and about the extent to which they form - despite differences a community, unity and a whole. The article emphasizes on one hand the dynamic, processual and creative nature of culture, and on the other its openness, consequently proving the utopian character of aspirations to establish once and for all an unchangeable 'essence' of culture as well as its timeless determinants and systemic framework. The article consists of three parts: 1) Context, subject and characteristics of culturology, 2) Delimitations of culture, 3) Acceleration, literacy, multiculturalism, culturalism.

Keywords: culturology, delimitations of culture, multiculturalism, culturalism 